\title{
Comparison of Elastic Strength Between High Pressure Vessels Having Circular and Elliptical Cross Bores at Radial and Offset Positions
}

\author{
P. K. NZIU and L. M. MASU \\ Department of Mechanical Engineering, Vaal University of Technology, South Africa.
}

ORCID: 0000-0002-5899-0700 (Dr PK Nziu), 0000-0002-8544-6321(Prof LM Masu)

\begin{abstract}
The purpose of this research was to compare the elastic strength between various sizes of high pressure vessels having circular and elliptical cross bores using two different analogies. The comparison consisted of a circular cross bore and two different elliptical cross bores at radial and offset positions. In the first analogy, the cross sectional area of one of the elliptical cross bore denoted as Elliptical CB1 was made equal to that of circular cross bore. Whereas, in the second analogy, the elliptical cross bore denoted as Elliptical CB 2 had its major diameter equal to that of the circular cross bore. The analyses were done on cross bored cylinders with thickness ratio ranging from 3.0 down to 1.4 using a 3D Abaqus 6.19 standard version software program. A total of 189 part models of thick walled cylinders with radial and offset cross bores were created and analysed using an eighth of the cylinder structure. It was found that the lowest overall magnitude of the working stresses was predicted by elliptical cross bore at the radial position for both Von Mises and Tresca theories. Irrespective of elliptical cross bore size of CB1 being twice of that of CB2, the difference in working stresses predicted by the two elliptical cross bores at the radial position was insignificant
\end{abstract}

On the other hand, the magnitude of working stresses predicted by the circular cross bore was observed to reduced progressively with increase in cross bore location ratio. Noticeably, there were instances in thickness ratios of 1.4 and 3 , where the working stresses magnitude given by circular cross bore and that of elliptical cross bores CB2 were the same across several offset positions. Overall, the pressure carrying capacity ranging from 24.7 to $34.7 \%$ can be reclaimed when the geometric parameters of the cross bore geometric are chosen optimally. The same behavioural trend seen in working stresses was replicated in the analyses of stress concentration factor (SCF).

Keywords: Pressure vessels, circular cross bore, elliptical cross bore, elastic strength, working stresses, Stress Concentration Factor

\section{INTRODUCTION}

High pressure vessels are used in most industrial operations to hold large amount of energy. Various theoretical principles such as elastic, elastoplastic and plastic are used in the design of pressure vessels (Hearn, 1999). Whenever, the elastic design principle is used, the working stresses are kept below the material yield stress to prevent yielding, a phenomenon termed as elastic strength (Masu,1997). Notable benefit for designing pressure vessels using elastic theory is the ability to withstand high number of cyclic loading exceeding $10^{5}$ cycles (Ford and Alexander, 1977).

Openings such as holes are some of the important parameters that are taken into consideration in the design of cylindrical pressure vessels. These openings provide provision for mounting essential accessories mainly for operation and maintenance (Nziu and Masu, 2019a). The openings can either be constructed on the vessel end enclosures or on the wall of the cylinder depending on the design (Masu,1998). Though, the latter is presumed to have higher strength than the former. Thus, whenever the opening is constructed on the wall of the vessel, the degree of weakness impacted on the vessel is greatly reduced. Previous studies had reported a reduction in pressure carrying capacity of $60 \%$ (Cole, 1969).

When the holes are constructed on the wall of the cylinder they are termed as cross bores. The effects of these cross bores on strength of the cylinder depend on their geometrical configuration such as size, obliquity, shape, location and the thickness of the vessel (Nziu and Masu, 2019b). Even though, the last three factors have been associated with more severe effects on elastic working stresses.

The most common cross bore shapes used in the pressure vessels design are circular and elliptical (Nziu and Masu, 2019c). However, there are two conflicting analogies on design principles of the cross bore between the two competing shapes. Some authors (Masu, 1998; Nziu, 2018) proposed comparison between the two shapes on the basis of major diameter of elliptical cross bore being equal to that of circular cross bore. Since it is assumed that elastic strength of the vessel depends mainly on the major diameter of the cross bore. In contrast, other authors (Kihiu, 2002; Adenya and Kihiu, 2010) suggested that comparison should be based on equal cross sectional areas between the two shapes. This approach enables equal discharge to be conveyed through the cross bore at any particular time by the two cross bore shapes. However, studies on the effects of these aforementioned analogies on elastic strength of the vessels, particularly on the cross bore location and vessel thickness ratios are not exhaustive. 
International Journal of Engineering Research and Technology. ISSN 0974-3154, Volume 13, Number 8 (2020), pp. 1814-1823

(C) International Research Publication House. https://dx.doi.org/10.37624/IJERT/13.8.2020.1814-1823

Therefore, this study seeks to compare elastic strength between circular and elliptical shaped cross bores in thick walled cylinders. Further, the study evaluates the effects of cross bore location and vessel thickness ratios on elastic strength, with an aim of improving the pressure holding capacity of the vessels.

\section{METHODOLOGY}

\section{Cross bore size and shape}

A circular cross bore was compared with two different elliptical shaped cross bores at radial and offset positions. The cross sectional area of one of the elliptical cross bore denoted as Elliptical CB1 was equal to that of the circular shaped cross bore. Whereas, the other cross bore denoted as Elliptical CB 2 had its major diameter equal to that of the circular one. Table 1 shows the actual dimensions of the cross bores.

Table 1 : Dimensions of the Cross bores

\begin{tabular}{|l|l|l|l|}
\cline { 2 - 4 } \multicolumn{1}{c|}{} & $\begin{array}{l}\text { Radius/Major } \\
\text { radius (a) }\end{array}$ & $\begin{array}{l}\text { Minor } \\
\text { radius (b) }\end{array}$ & $\begin{array}{l}\text { Cross } \\
\text { sectional } \\
\text { area }\end{array}$ \\
\hline Circular & 0.0025 & -- & $\begin{array}{l}1.968 \\
\times 10^{-5} \mathrm{~m}^{2}\end{array}$ \\
\hline $\begin{array}{l}\text { Elliptical } \\
\text { CB 1 }\end{array}$ & $0.00354 \mathrm{~m}$ & $0.00177 \mathrm{~m}$ & $\begin{array}{l}1.968 \\
\times 10^{-5} \mathrm{~m}^{2}\end{array}$ \\
\hline $\begin{array}{l}\text { Elliptical } \\
\text { CB 2 }\end{array}$ & $0.0025 \mathrm{~m}$ & $0.00125 \mathrm{~m}$ & $\begin{array}{l}9.81747 \\
\times 10^{-6} \mathrm{~m}^{2}\end{array}$ \\
\hline
\end{tabular}

The two elliptical shaped cross bores had optimum diameter ratio $(\mathrm{a} / \mathrm{b})$ of 2 . Figure 1 illustrates the configuration arrangement of the three cross bores used.

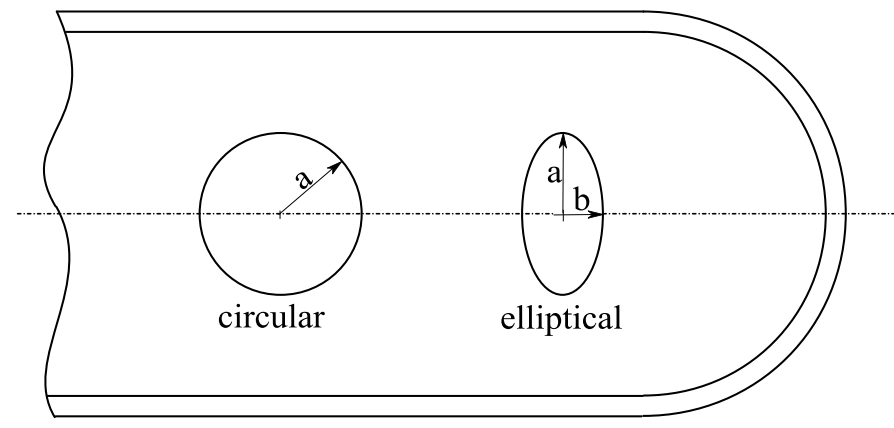

Figure 1. Cross bore configuration

Where $\mathrm{a}$ is the radius/ major radius and $\mathrm{b}$ is the minor radius

\section{Cylinder thickness ratio}

Cylinders with thickness ratios ranging from 1.4 to 3.0 were analysed. The actual sizes of cylinder thickness ratios that were studied are tabulated in Table 2

Table 2: Cylinder thickness ratio

\begin{tabular}{|l|l|l|l|l|l|l|l|}
\cline { 2 - 7 } \multicolumn{1}{|c|}{ Sizes of cylinder thickness ratio } \\
\hline $\mathrm{K}$ & 1.4 & 1.5 & 1.75 & 2.0 & 2.25 & 2.5 & 3.0 \\
\hline
\end{tabular}

For effective comparison of the generated results, the bore diameter of the cylinders was kept constant throughout the study at $0.05 \mathrm{~m}$.

\section{Cross bore location}

The study was carried out at various cross bore locations across the global $\mathrm{X}$ axis plane of the cylinder as illustrated in Figure 2.

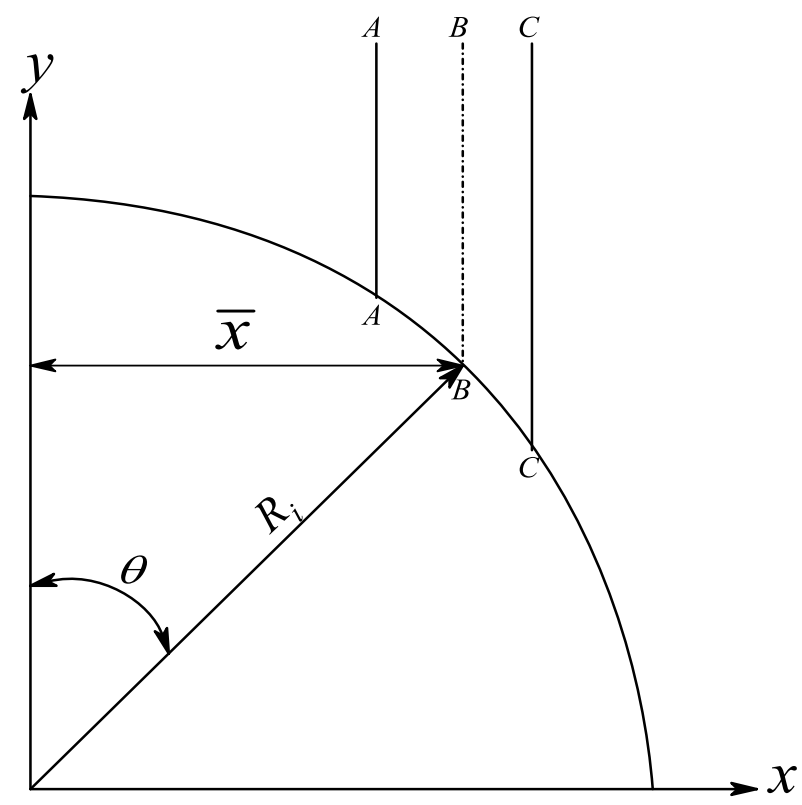

Figure 2. Configuration of the cross bore location

For ease of the analyses, each cross bore location was converted to an offset location ratio by dividing the actual offset distance $\bar{x}$, with the main bore radius $\mathrm{R}_{\mathrm{i}}$, i.e., $\overline{\mathrm{x}} / \mathrm{R}_{\mathrm{i}}$. The actual locations ratios studied are tabulated in Table 3 .

Table 3: Cross bore location ratios

\begin{tabular}{|c|c|c|c|c|c|c|c|c|c|}
\cline { 2 - 7 } \multicolumn{1}{c|}{} & \multicolumn{10}{c|}{ Cross bore locations ratios } \\
\hline $\begin{array}{c}\text { Offset } \\
\text { ratio }\end{array}$ & 0 & 0.12 & 0.24 & 0.36 & 0.48 & 0.58 & 0.685 & 0.79 & 0.9 \\
\hline
\end{tabular}

\section{Finite Element Analysis}

A total of 189 part models of thick walled cylinders with radial and offset cross bores were created and analysed using a 3D Abaqus 6.19 standard version software program. Due to the symmetrical nature of the cylinders, only $1 / 8$ of the structure 
was used. The major modelling procedures adopted in this study are briefly described in the proceeding section.

The part model was created by first drawing the face of the cylinder. The cylinder face was then extruded to form the depth of the cylinder. The depth of the cylinder was three times the external diameter of the cylinder so as to restrict transmission of end closures effects to the other end of the cylinder. Cut extrude and cut revolve tools were used to create radial and offset cross bores, respectively. Figure 3 and 4 shows model profiles created at radial and offset positions.

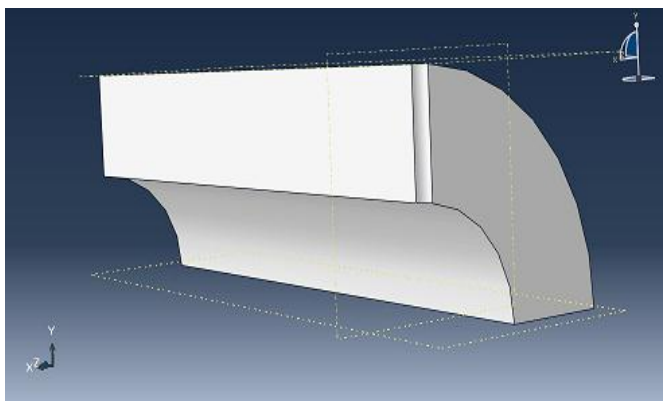

Figure 3. Part profile of radial cross bore

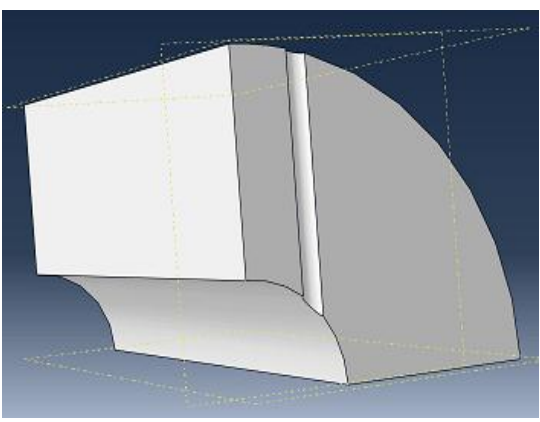

Figure 4. Part profile of an offset cross bore

Symmetrical boundary conditions were applied on the three global planes at the cut sections to enforce correct symmetry. Besides, the application of boundary conditions restrains the model from performing unlimited motions during the modelling process. The displacement in axial direction of the cylinder was suppressed to generate axial stresses since the cylinders were closed. Both the main bore and cross bore were then loaded with internal pressure. This was followed by the selection of Von Mises's and Tresca's working stresses as the field output request.

The complete meshing process of each model was achieved in two stages. In the first stage, the model was partitioned into small geometrical sections. The sizes of these geometrical sections in the region around the cross bore were reduced to 0.003 and $0.004 \mathrm{~m}$ so as to capture accurately the local working stresses. Whereas, the second stage of model meshing involved the choice of modelling elements. In all the radial positions of the cross bore, 20-noded second order C3D20R hexahedral (brick) isoparametric elements were selected for modelling. On the other hand, second order C3D10 tetrahedral elements with 10 nodes were chosen for all the offset positions. Figures 5 and
6 illustrate the meshed profiles of radial and offset cross bores.

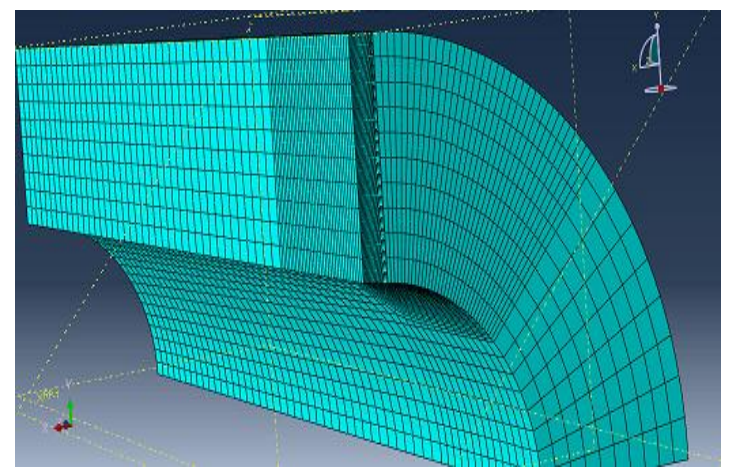

Figure 5. Radial cross bore mesh profile

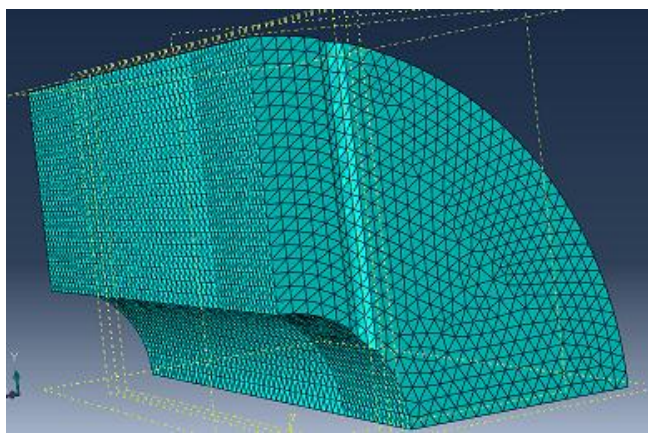

Figure 6. Offset Cross bore mesh profile

\section{Validation of the model}

Analytical and experimental methods were used to authenticate the FEA results generated in this modelling. FEA results from the regions far away from the cross bore, (that is a linear length exceeding 2.5 cross bore diameter), were compared with those obtained using the analytical method. Since it was assumed that the effects of the cross bore is limited to the region within the aforesaid length (Ford and Alexander, 1977). On the other hand, similar experimental data obtained from the reviewed literature (Masu,1989) was used to validate the FEA results further.

\section{Working stress concentration factor}

In this work, theoretical stress concentration factor (SCF) was defined as the ratio of localised maximum working stresses in a cross bored cylinder to the corresponding working stresses in a similar plain cylinder (Ford and Alexander, 1977). It is important to mention that in cross bored cylinders, the maximum working stresses do not always occur at the intersection between the main bore and the cross bore, commonly referred to as nominal area. This is because the working stresses at the nominal area increase rapidly until they reach yield point. Eventually, the material deforms permanently at those points resulting in reduction of the working stresses. Therefore, the maximum working stresses tend to occur away from the intersection. Due to this peculiar behaviour of working stresses, the theoretical stress concentration factor is preferred for these analyses. 
International Journal of Engineering Research and Technology. ISSN 0974-3154, Volume 13, Number 8 (2020), pp. 1814-1823

(C) International Research Publication House. https://dx.doi.org/10.37624/IJERT/13.8.2020.1814-1823

\section{RESULTS AND DISCUSSION}

Cross bore geometric configuration effects on working stresses

Figures 7 to 20 show the comparison of Von mises and Tresca's working stresses predicted at different cross bore locations by

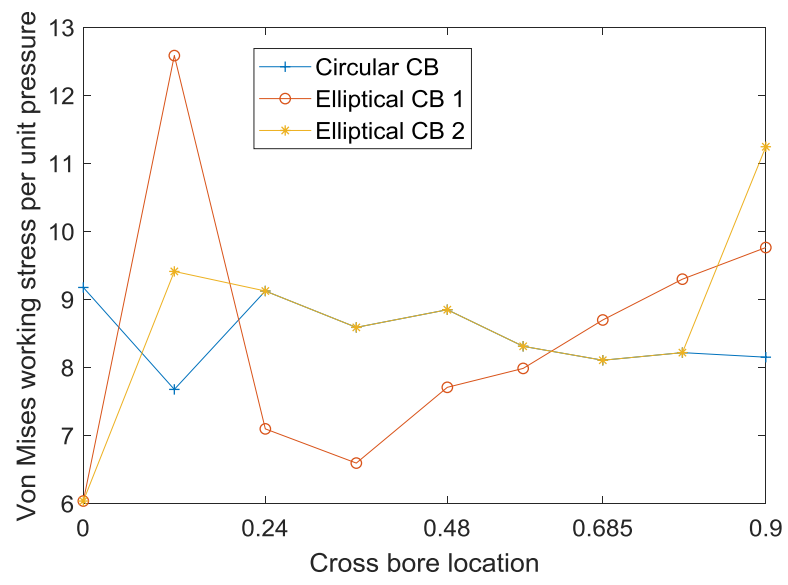

Figure 7: Von Mises stress for $\mathrm{K}=1.4$

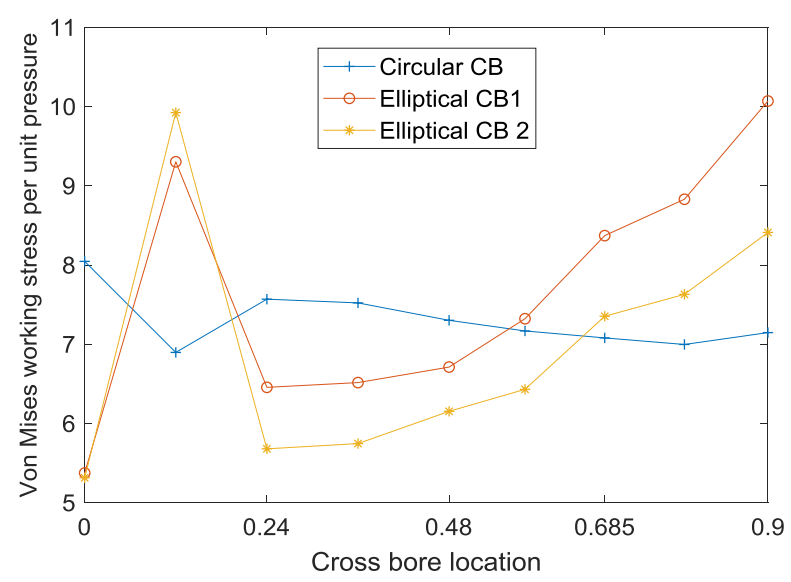

Figure 9: Von Mises stress for $\mathrm{K}=1.5$

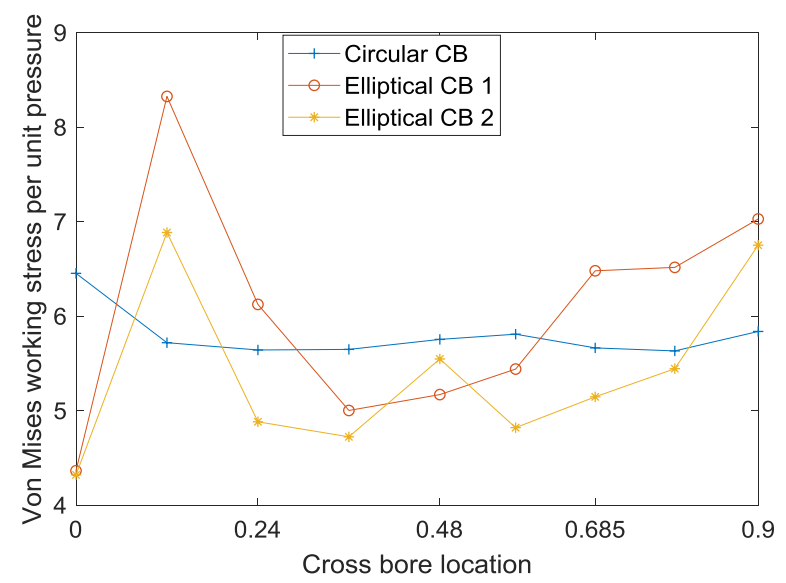

Figure 11: Von Mises for $\mathrm{K}=1.75$ circular and elliptical cross bores for thickness ratios, $\mathrm{K}=1.4$, $1.5,1.75,2.0,2.25,2.5$ and 3.0.

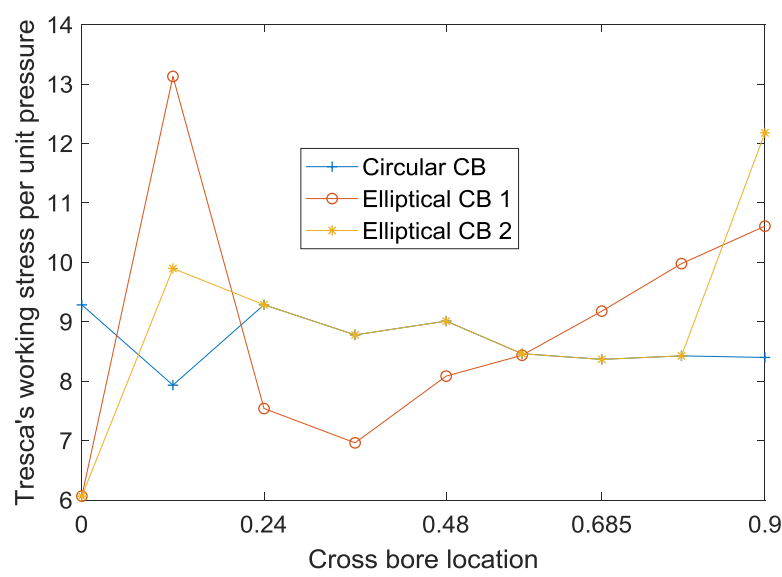

Figure 8: Tresca stress for $\mathrm{K}=1.4$

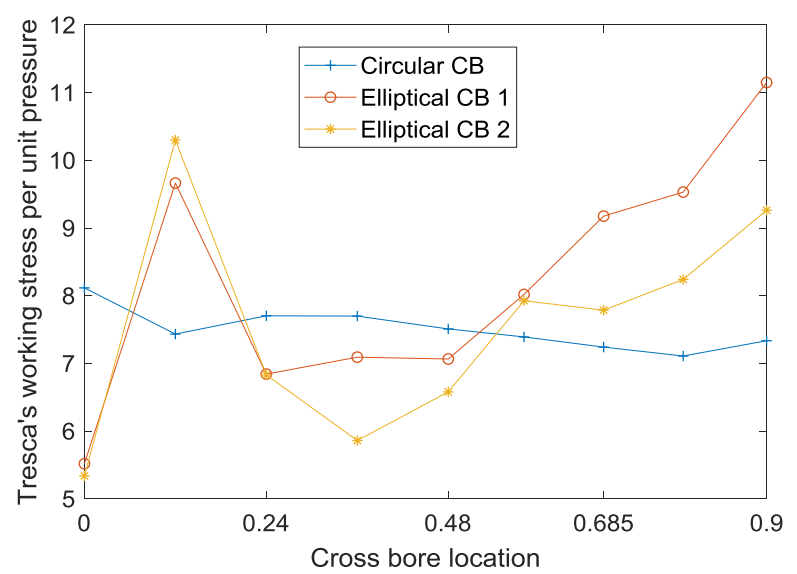

Figure 10: Tresca stress for $K=1.5$

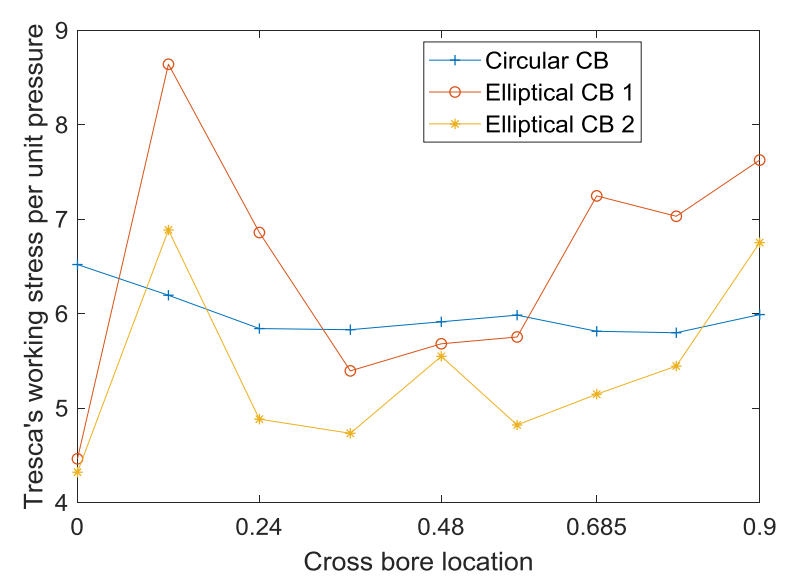

Figure 12: Tresca stress for $K=1.75$ 
International Journal of Engineering Research and Technology. ISSN 0974-3154, Volume 13, Number 8 (2020), pp. 1814-1823

(C) International Research Publication House. https://dx.doi.org/10.37624/IJERT/13.8.2020.1814-1823

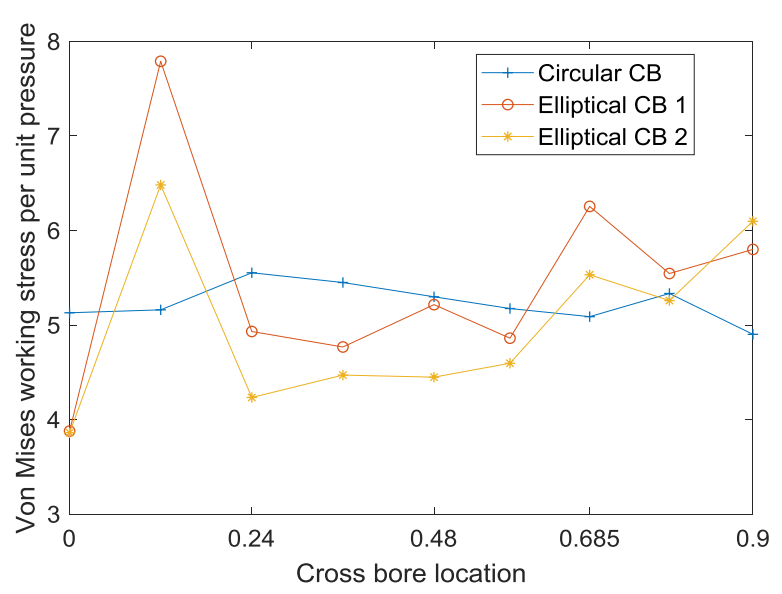

Figure 13: Von Mises for $K=2.0$

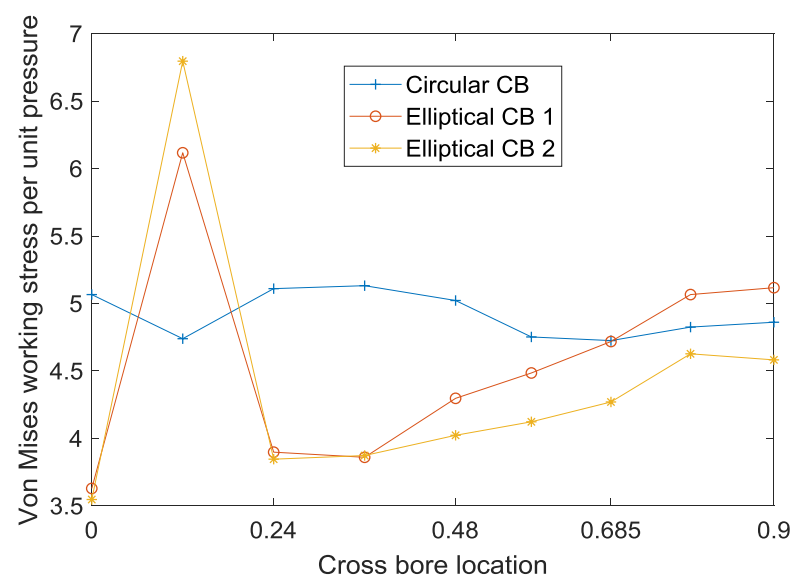

Figure 15: Von Mises for $K=2.25$

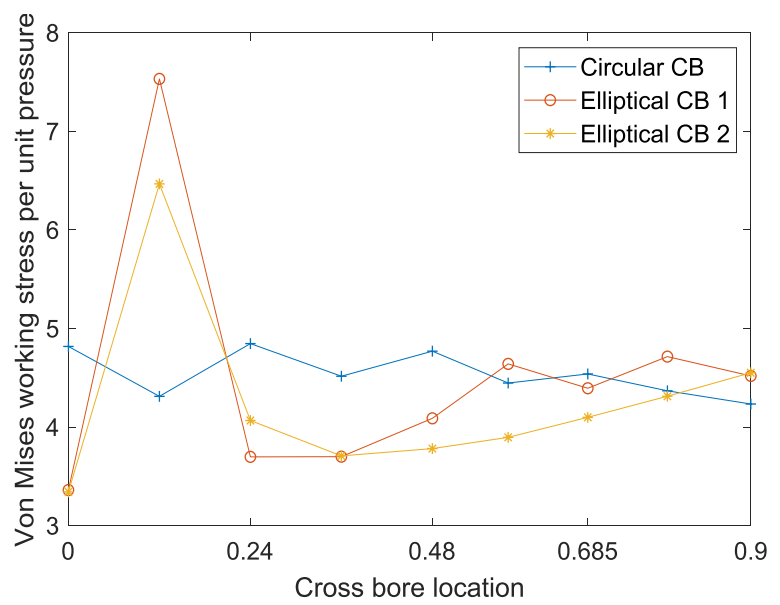

Figure 17: Von Mises for $K=2.5$

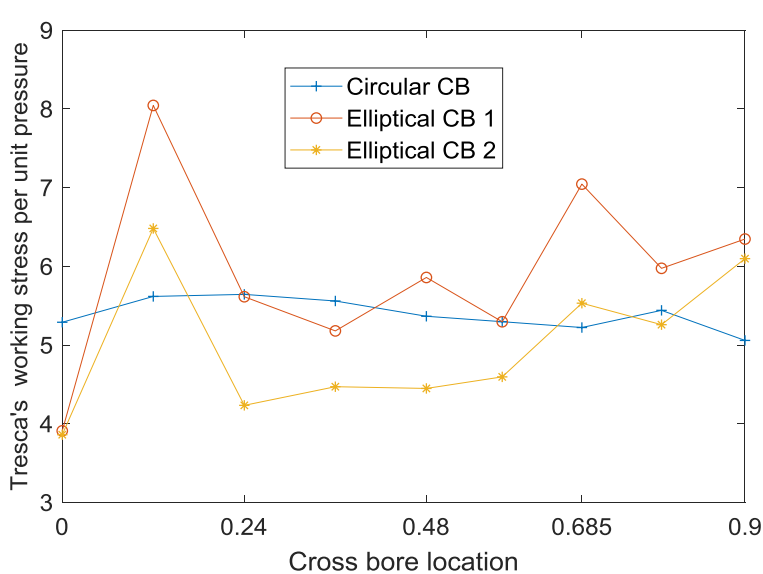

Figure 14: Tresca for $K=2.0$

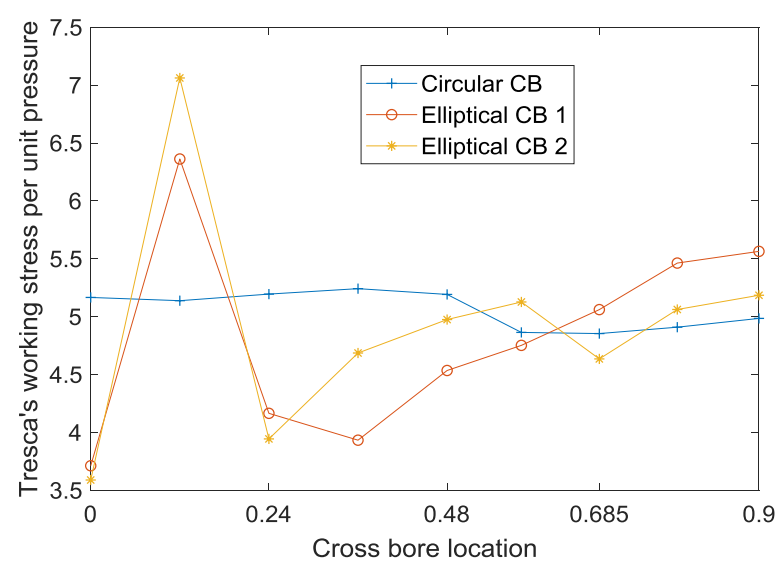

Figure 16: Tresca for $K=2.25$

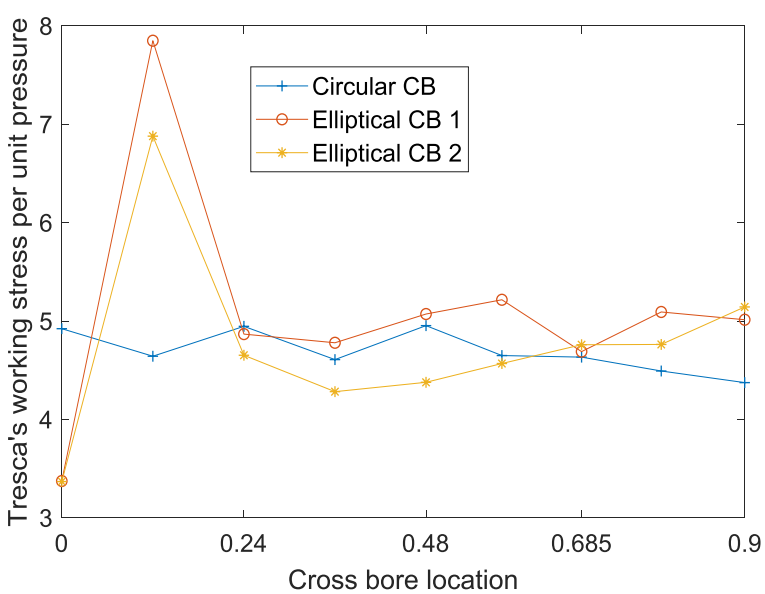

Figure 18: Tresca for $K=2.5$ 


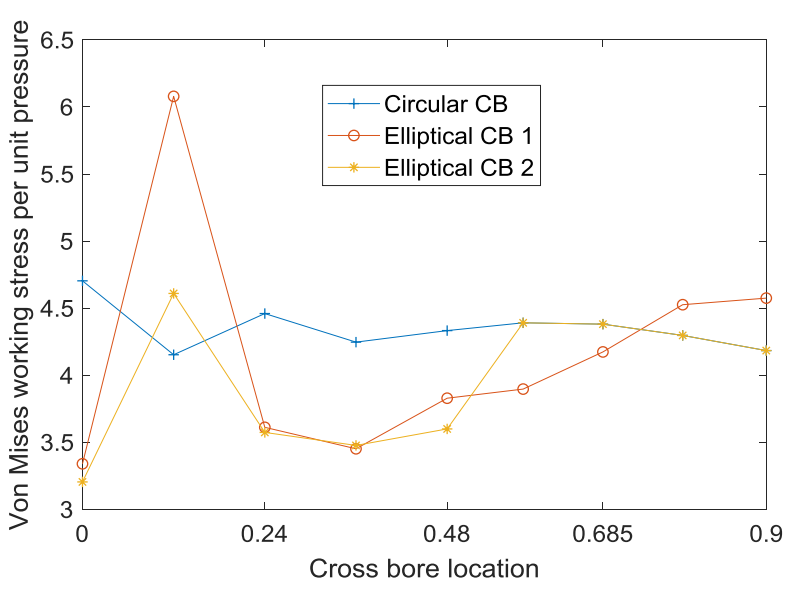

Figure 19: Von Mises for $K=3.0$

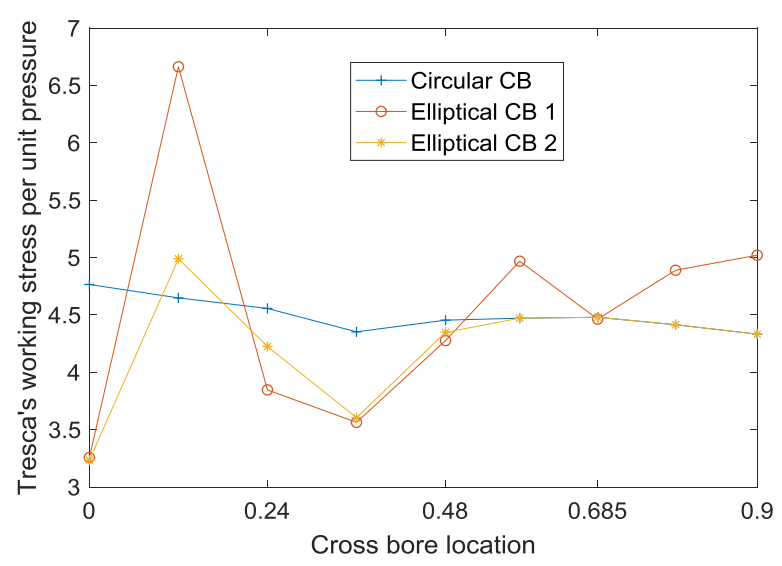

Figure 20: Tresca for $K=3.0$
Despite the difficulties associated with its construction, the lowest overall magnitude of the working stresses were predicted by elliptical shaped cross bore at the radial position for both Von Mises and Tresca theories. Irrespective of elliptical cross bore size of $\mathrm{CB} 1$ being twice that of $\mathrm{CB} 2$, the difference in working stresses predicted by the two elliptical cross bores at the radial position was insignificant. This occurrence indicated that the cross bore size of an elliptical cross bore had minimal effects at radial position. Probably, thus the reason why most design analogies tended to ignore the size effects of elliptical cross bores (Harvey, 1985). Besides, most of the reviewed studies on elliptical cross bore were done at radial position.

In contrast, significant difference in magnitude of working stresses were noted between the two sizes of the elliptical cross bores when they were positioned in offset positions. This observation justified the analogy of taking into account the size effects of an elliptical cross bore, particularly at offset positions. In addition, the two elliptical cross sections had sharp working stress peaks at cross bore location ratio of 0.12 . However, low working stress magnitudes were predicted alternately by either elliptical cross bore size $\mathrm{CB} 1$ or $\mathrm{CB} 2$ between location ratios of 0.24 and 0.36 .

On the other hand, the magnitude of working stresses predicted by the circular cross bore was observed to reduce progressively with increase in cross bore location ratio. With the exception of $\mathrm{K}=2.25$ for Von Mises theory (Figure 15), the magnitude of the working stresses given by the circular cross bore were lowest at the cross bore offset position ratio of 0.9 . Though, the stress difference given by Von Mises theory between the circular cross bore and that of elliptical CB 2 was $5.73 \%$.

Noticeably, there were instances in $\mathrm{K}=1.4$ and 3.0 (Figures 7, 8, 19 and 20), where the working stresses magnitudes given by circular cross bore and that of elliptical cross bore CB2 were the same across several offset positions.

Generally, in an offset circular cross bore, the cross bore axis does not intersect with that of the main bore. As a result, when the configuration is viewed at the intersection of the crossbore and main bore it resembles a slender elliptical hole having major and minor diameters. The major diameter, denoted as ' $a$ ' (see figure 1) increases with increase in the location ratio. Whereas, the corresponding minor diameter, denoted as ' $b$ ' reduces. A diametric configuration where $\mathrm{a}>\mathrm{b}$ leads to reduction in working stress as cited by Cheng (1978) and Harvey (1985) studies.

On the other hand, when the configuration of an offset elliptical cross bore is viewed at the intersection between the cross bore and the main bore it resembles an ellipse. Similar to the elliptical cross bore, an ellipse has major and minor diameter denoted as "a" and "b", respectively. The minor diameter increases with increase in offset location and vice versa. Hence, the diametric configuration where $a<b$ results in high magnitudes of working stresses as cited by Cheng (1978) and Harvey (1985) research work.

It is worthwhile to note that the behaviour of diametric configuration of offset elliptical cross bores were opposite to those observed in offset circular cross bores. An indication that at one particularly offset point, the images of circular and elliptical when viewed at the cross bore intersection will be identical. This analogy explains why at certain location ratios the working stress magnitudes predicted between circular and elliptical cross bores were equal.

Since the optimal working stresses occurred at the radial location. The amount of lost pressure carrying capacity that can be reclaimed at the radial position when the geometric design parameters of the cross bore are appropriately chosen is presented in Table 4.

Table 4: Reclaimed pressure holding capacity between circular and elliptical cross bore at radial position

\begin{tabular}{|c|c|c|}
\hline $\begin{array}{c}\text { Thickness } \\
\text { ratio }\end{array}$ & Theory used & $\begin{array}{c}\text { Reclaimed pressure } \\
\text { holding capacity (\%) }\end{array}$ \\
\hline \multirow{2}{*}{1.4} & Von Mises & 34.2 \\
\cline { 2 - 3 } & Tresca & 34.7 \\
\hline \multirow{2}{*}{1.5} & Von Mises & 33.9 \\
\cline { 2 - 3 } & Tresca & 34.2 \\
\hline \multirow{2}{*}{1.75} & Von Mises & 33.1 \\
\hline
\end{tabular}


International Journal of Engineering Research and Technology. ISSN 0974-3154, Volume 13, Number 8 (2020), pp. 1814-1823

(C) International Research Publication House. https://dx.doi.org/10.37624/IJERT/13.8.2020.1814-1823

\begin{tabular}{|c|c|c|}
\hline $\begin{array}{c}\text { Thickness } \\
\text { ratio }\end{array}$ & Theory used & $\begin{array}{c}\text { Reclaimed pressure } \\
\text { holding capacity (\%) }\end{array}$ \\
\hline \multirow{2}{*}{2.0} & Tresca & 33.4 \\
\cline { 2 - 3 } & Von Mises & 24.7 \\
\hline \multirow{2}{*}{2.25} & Tresca & 26.7 \\
\cline { 2 - 3 } & Von Mises & 29.9 \\
\hline \multirow{2}{*}{2.5} & Tresca & 30.5 \\
\cline { 2 - 3 } & Von Mises & 30.6 \\
\hline \multirow{2}{*}{3.0} & Tresca & 31.6 \\
\cline { 2 - 3 } & Von Mises & 31.9 \\
\cline { 2 - 3 } & Tresca & 32.1 \\
\hline
\end{tabular}

From table 4 , it can be seen that pressure carrying capacity ranging from 24.7 to $34.7 \%$ can be reclaimed when the cross bore geometric parameters are chosen optimally. However, this range of possible reclaimed capacity is approximately half of $60 \%$ reported to have been lost due to the construction of the cross bore by Cole (1969) study.

Cross bore geometric configuration effects on working stress concentration factor

Figures 21 to 34 show the comparison of working stress concentration factors predicted at different cross bore locations by circular and elliptical cross bores for thickness ratios, $\mathrm{K}=$ $1.4,1.5,1.75,2.0,2.25,2.5$ and 3.0.

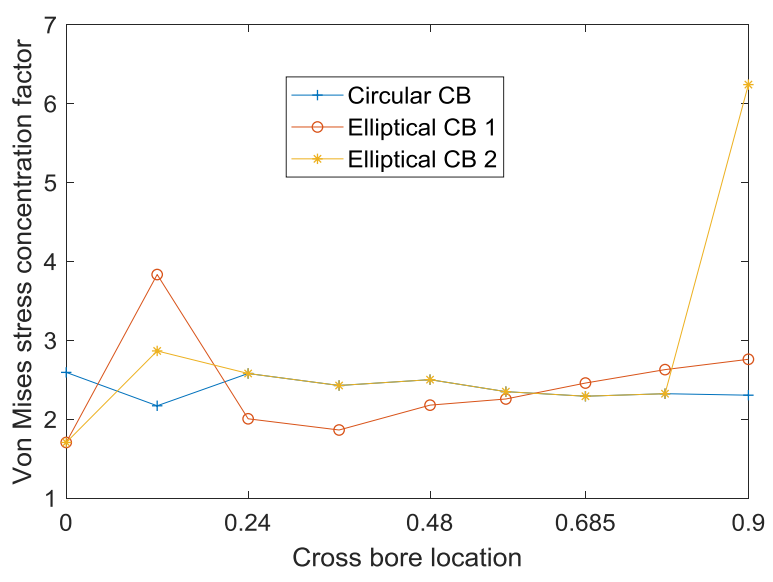

Figure 21: Von Mises SCF for $\mathrm{K}=1.4$

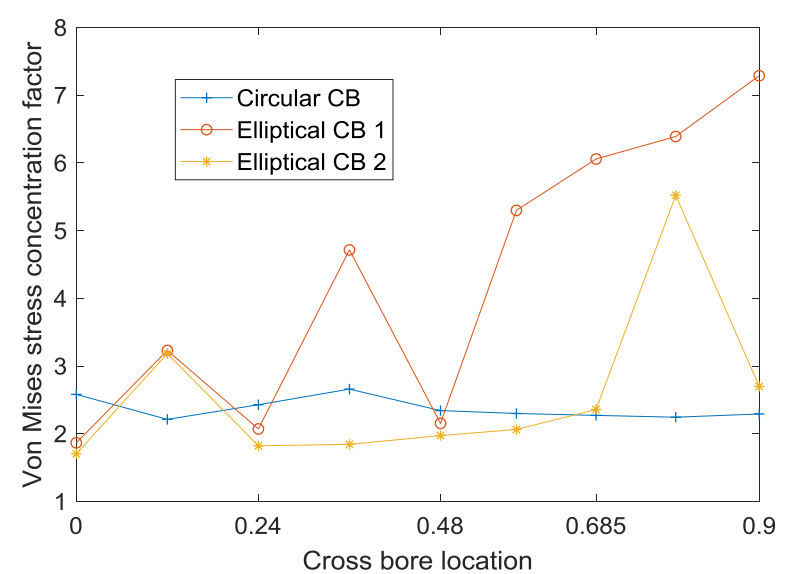

Figure 23: Von Mises SCF for $\mathrm{K}=1.5$

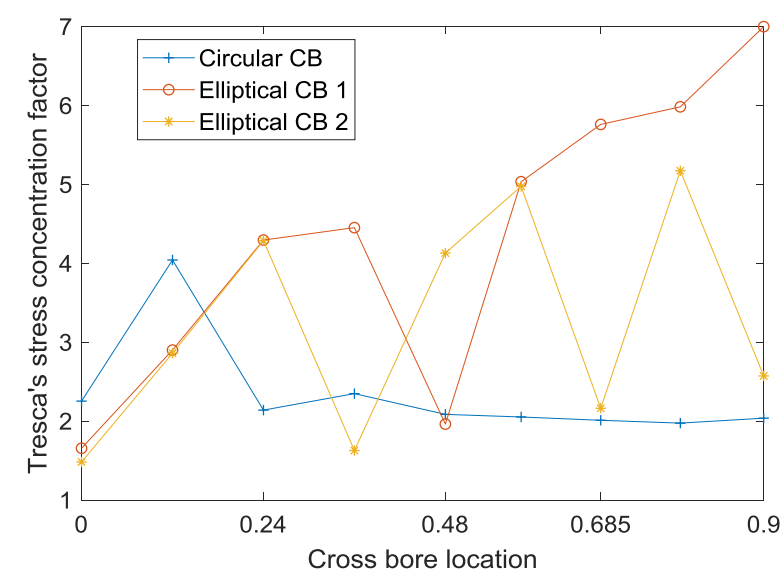

Figure 24: Tresca SCF for $K=1.5$ 
International Journal of Engineering Research and Technology. ISSN 0974-3154, Volume 13, Number 8 (2020), pp. 1814-1823

(C) International Research Publication House. https://dx.doi.org/10.37624/IJERT/13.8.2020.1814-1823

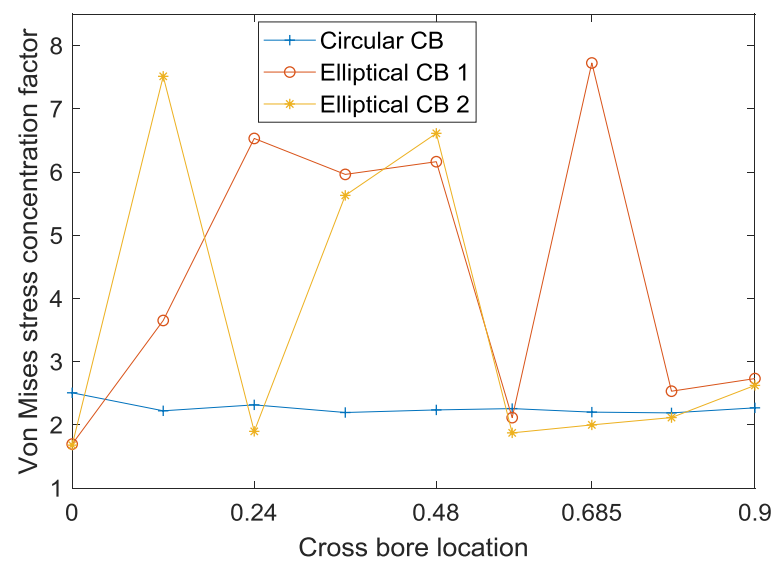

Figure 25: Von Mises SCF for $\mathrm{K}=1.75$

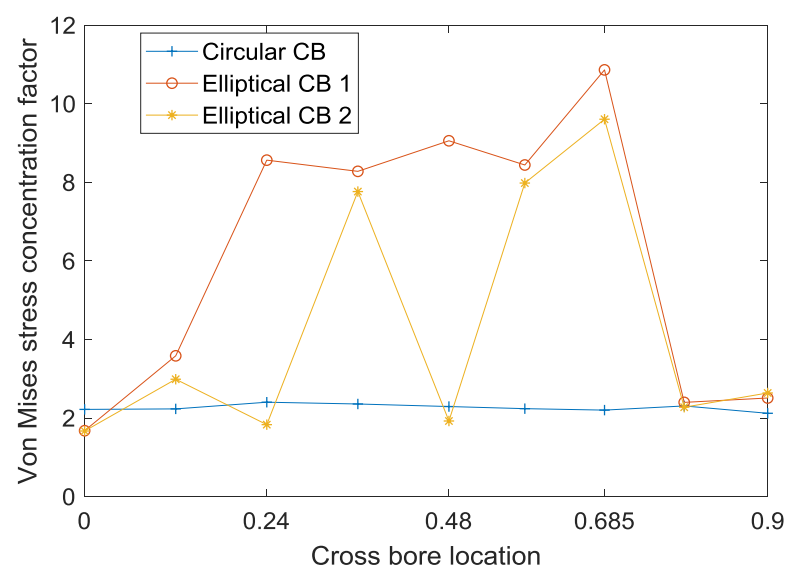

Figure 27: Von Mises SCF for $\mathrm{K}=2.0$

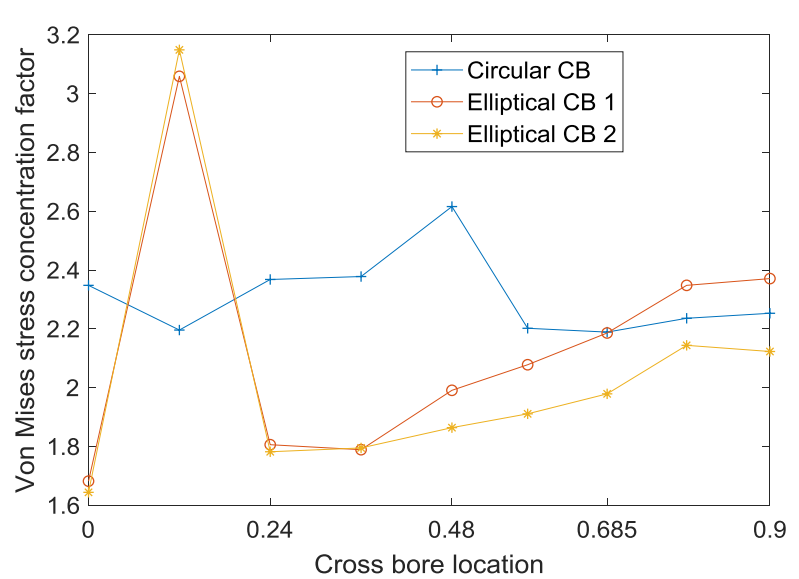

Figure 29: Von Mises SCF for $\mathrm{K}=2.25$

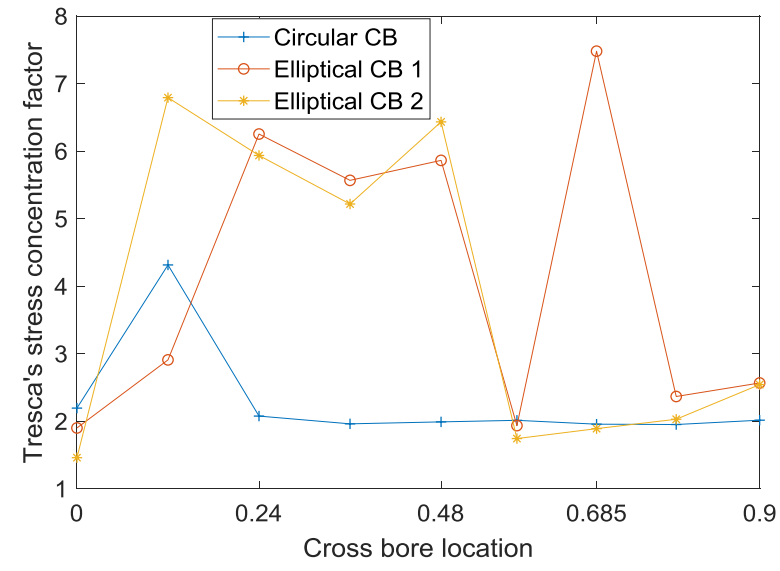

Figure 26: Tresca SCF for $K=1.75$

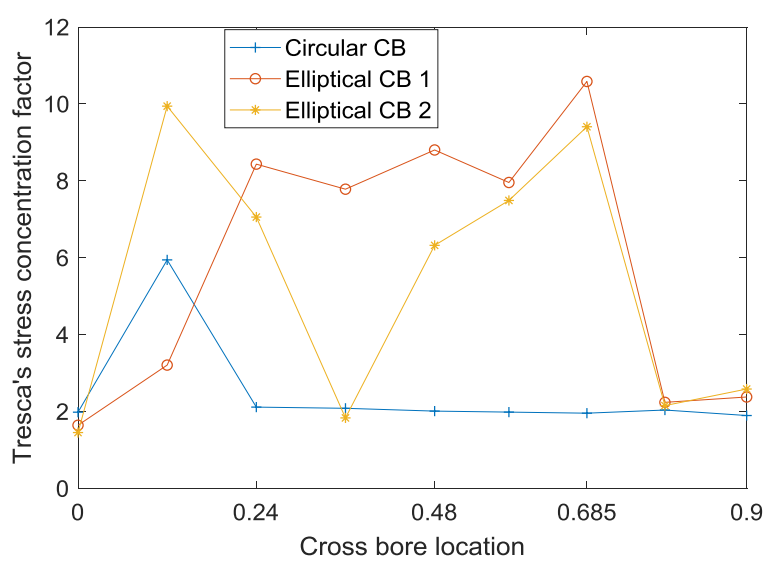

Figure 28: Tresca SCF for $K=2.0$

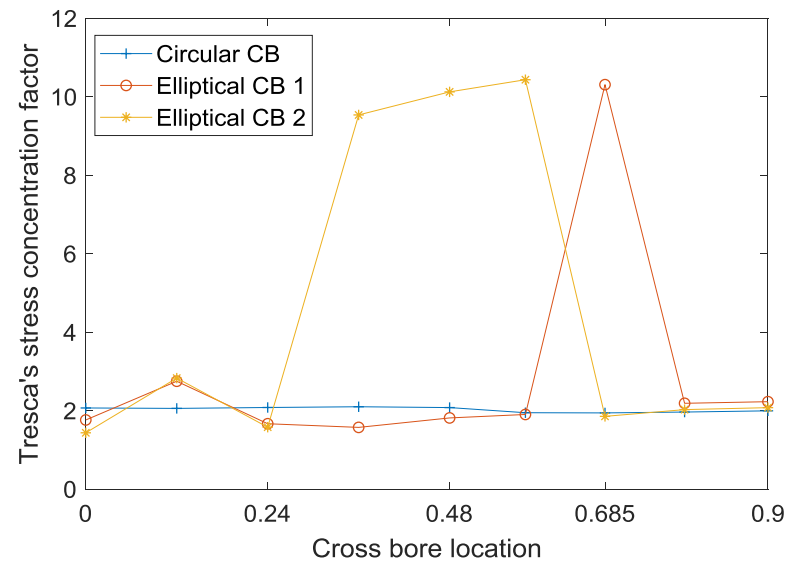

Figure 30: Tresca $\mathrm{SCF}$ for $\mathrm{K}=2.25$ 


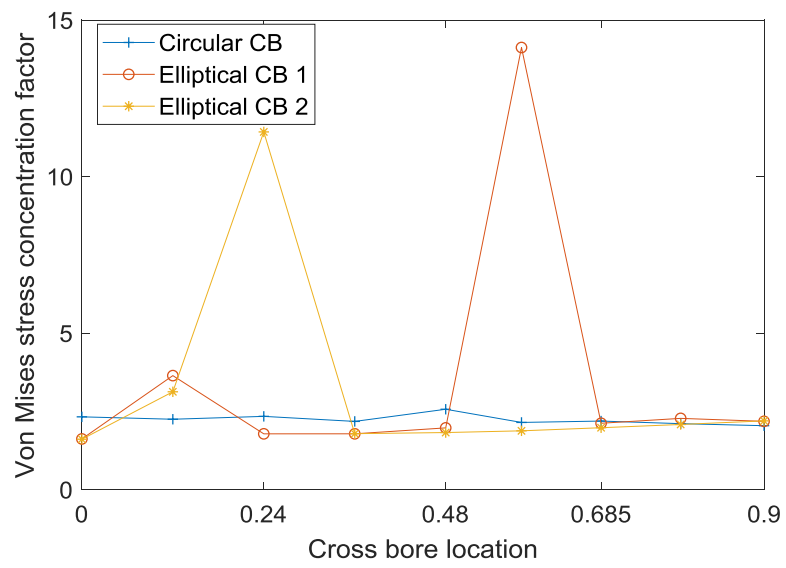

Figure 31: Von Mises SCF for $\mathrm{K}=2.5$

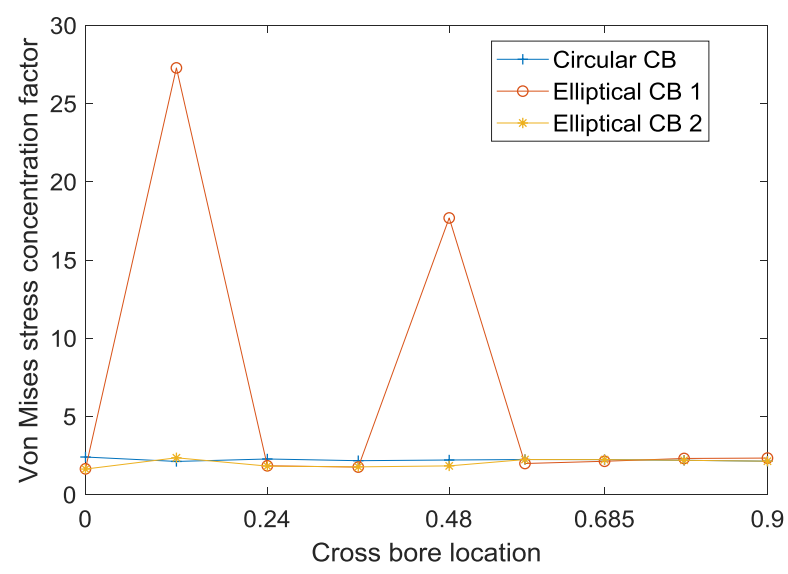

Figure 33: Von Mises SCF for $\mathrm{K}=3.0$

Similar to the preceding section, the elliptical shaped cross bore gave the lowest SCF magnitudes at the radial position. Table 5 shows a SCF comparison with other related studies at radial position.

Table 5: Comparison of SCF magnitudes at radial position

\begin{tabular}{|l|c|c|c|c|}
\hline $\begin{array}{l}\text { Cross bore } \\
\text { shape }\end{array}$ & \multicolumn{2}{|c|}{ Circular } & \multicolumn{2}{|c|}{ Elliptical } \\
\hline Theory used & Von Mises & Tresca & Von Mises & Tresca \\
\hline $\begin{array}{l}\text { Current } \\
\text { study }\end{array}$ & $2.22-2.6$ & $1.98-2.25$ & $1.621-1.708$ & $1.415-1.902$ \\
\hline Cole (1969) & 2.88 & 2.5 & 1.703 & 1.695 \\
\hline $\begin{array}{l}\text { Ford \& } \\
\begin{array}{l}\text { Alexander } \\
(1976)\end{array}\end{array}$ & 2.89 & 2.5 & - & - \\
\hline
\end{tabular}

As seen in table 5, SCF results from the current study compared favorably with those presented in the literature. All other offset positions gave high magnitudes of SCF.

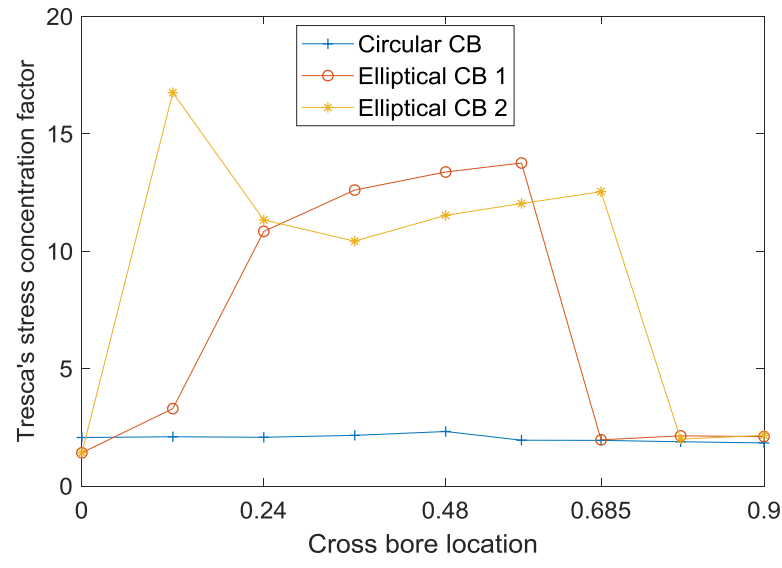

Figure 32: Tresca $\mathrm{SCF}$ for $\mathrm{K}=2.5$

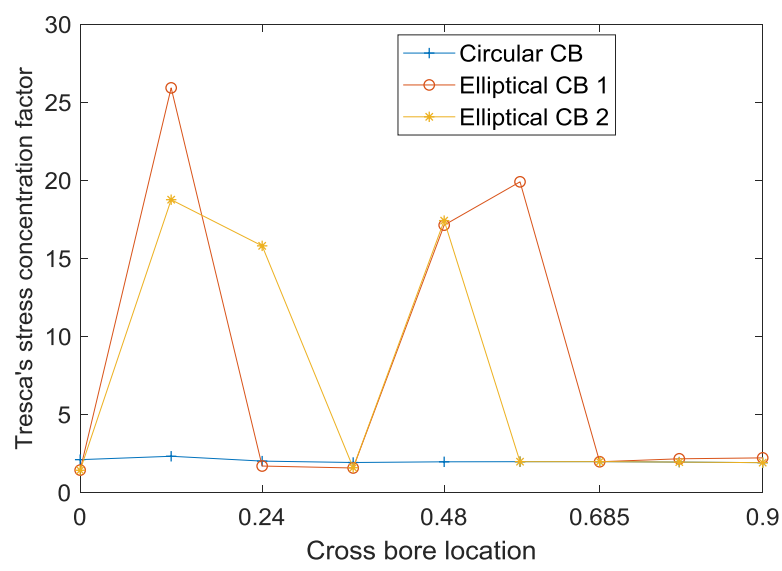

Figure 34: Tresca SCF for $K=3.0$

\section{CONCLUSION}

1. The lowest overall magnitude of the working stresses were predicted by elliptical shaped cross bore at the radial position for both Von Mises and Tresca theories.

2. Irrespective of elliptical cross bore size of $\mathrm{CB} 1$ being twice that of $\mathrm{CB} 2$, the difference in working stresses predicted by the two elliptical cross bores at the radial position was insignificant

3. The magnitude of working stresses predicted by the circular cross bore was observed to reduce progressively with increase in cross bore location ratio.

4. There were instances in $\mathrm{K}=1.4$ and 3, where the working stress magnitudes given by the circular cross bore and that of elliptical cross bores CB2 were the same across several offset positions.

5. The pressure carrying capacity ranging from 24.7 to 34.7 $\%$ can be reclaimed when the cross bore geometric parameters are chosen optimally.

6. The elliptical shaped cross bore gave the lowest SCF magnitudes at the radial position 
International Journal of Engineering Research and Technology. ISSN 0974-3154, Volume 13, Number 8 (2020), pp. 1814-1823

(C) International Research Publication House. https://dx.doi.org/10.37624/IJERT/13.8.2020.1814-1823

\section{ACKNOWLEDGEMENTS}

This work was supported by the Department of Mechanical Engineering, Vaal University of Technology, South Africa.

\section{REFERENCES}

[1] Adenya, C.A. and Kihiu, J. M. (2010), "Stress concentration factors in thick walled cylinders with elliptical cross bore", Master's thesis, Jomo Kenyatta University of Science and Technology.

[2] Cheng, Y. F. (1978), "Stress concentration around inclined holes in pressurized thick-walled cylinders" Technical Report -Arlcb-TR-78019.

[3] Cole BN (1969)," Strategy for cross bore in high pressure containers", Journal mechanical engineering science Vol 11. No.2 pp 151-161

[4] Ford, H. and Alexander, J. (1977), “Advanced mechanics of materials", John wiley and sons inc., Canada, second edition.

[5] Harvey, J. F. (1985), "Theory and design of pressure vessels", Van Nostrand Reinhold Company Inc., ISB No. 0-442-23248-9.

[6] Hearn, E. J. (1999), "Mechanics of materials 2", Butterworth-Heinemann, Great Britain, ISBN 0-7506 3266-6, Third edition.

[7] Kihiu, J. M. (2002), "Numerical stress characterization in cross bored thick walled cylinders under internal pressure", The University of Nairobi, $\mathrm{PhD}$ thesis.

[8] Masu, L. M. (1989), "The effect of cross bore geometry on the strength of pressure vessels", $P h D$ thesis, University of leeds.

[9] Masu, L. M. (1997), "Cross bore configuration and size effects on the stress distribution in thick-walled cylinders", International journal of pressure vessels and piping, No. 72, pp. 171-176.

[10] Masu, L. M. (1998), "Numerical analysis of cylinders containing circular offset cross bores", International journal of pressure vessels and piping, No. 75, pp. 191196.

[11] Nziu P. K. (2018), “Optimal geometric configuration of a cross bore in high pressure vessels" Doctorate thesis, Vaal University of Technology.

[12] Nziu, P.K. and Masu, L. M. (2019a) "Elastic strength of high pressure vessels with a radial circular cross bore”, International journal of mechanical and production engineering research and development, ISSN 2249-6890, Vol.9, issue 3, pp. 1275-1284, doi:10.24247/ijmperdjun2019133.

[13] Nziu, P.K. and Masu, L. M. (2019b) "Formulae for predicting stress concentration factors in flat plates and cylindrical pressure vessels with holes: A review", International journal of mechanical and production engineering research and development, ISSN 2249-6890,
2019, Vol. 9, issue 5, pp. 753-770, doi: 10.24247/ ijmperdoct 201967

[14] Nziu, P.K. and Masu, L. M. (2019c), "Configuration of optimal cross bore shape in elastic pressurized high pressure", International journal of mechanical and production engineering research and development, ISSN 2249-6890,Vol. 9, issue 5, pp. 197-210, doi: 10.24247/ ijmperdoct 201918 